\title{
Socio-Culture Factors Responsible for Crimes Committed by Females of Adiala Jail, Rawalpindi, Pakistan
}

\author{
Asma Zafar \\ Sociology \& Anthropology Department, \\ PMAS Arid Agriculture University Rawalpindi \\ Muhammad Asim \\ E.Mail.I.D:masim202@gmail.com \\ M. Phil Scholar, Department of Sociology, \\ Government College University Faisalabad, Pakistan \\ Nazia Malik \\ Assistant Professor, Department of Sociology, \\ G.C University Faisalabad, Pakistan \\ Muhammad Iqbal Zafar \\ Dean faculty of social sciences, \\ University of Agriculture Faisalabad, Pakistan
}

Doi:10.5901/ajis/2013.2n1p373

\section{Abstract}

The present study was designed to determine the socio-cultural factors responsible for crimes committed by females. The data was collected from Adiala Jail situated in Rawalpindi district by interviewing a sample of IOO female respondents. The data was collected by a well designed interview schedule and by using statistical techniques. As per research achievements of the project, it was concluded that $51 \%$ of female offenders were predominantly from rural areas which denotes poor education and income condition of the people. Majority i.e. $87 \%$ of the females were not affected by any circumstances like any psychological change due to imprisonment. Significant association between income and socio-cultural factors responsible for crimes conducted by females was noted.

Key Words: Crime, Socio-cultural factors, Adiala Jail, Rawalpindi

\section{Introduction}

Crime and criminology is identified item of genetic composition for instance; male crime, juvenile delinquency and women crimes (Smith, 1995). Crime is relative concept. This is important since an act is a crime only in a particular social setting and period of time. Just as criminal law varies from area to area, it can change from time to time within the same area as well. Crime is an act which breaks the criminal law. However, criminal law is not fixed or static; it varies overtime and from area to area (Marsh, 1986) Crime an d criminology is very vast field so the difference is identified item of genetic 
composition for instance male crime, juvenile delinquency and women crime. Female criminality is one of the major social problem of all the country, which needs attention of the state and the social scientists. Criminality is simply not something people do and other's do not, crime is merely a matter of who can pin the label on whom and under line this socio political process is the structure of social relation determined by the political economy (Chambliss, 1975) to study female crime or criminality in Pakistan one must understand the cultural definition of women and the male of their sexuality, which steams from it. The extreme dichotomization between the sexes which exists in most Islamic and Middle Eastern culture (Pastner, 1974) The reporting of female crimes is not so efficient due to various sociocultural factors for instance. For instance female criminality is mostly ignored and their crimes are not reported to police (Chaudhry, 1984)

Women are physically weak, legally and economically inferior to men. Their honor their property and their lives are therefore susceptible to exploitation by the arbitrary whims of males. This is particularly true since men are by nature aggressive and women are by protected the function of modesty code is to offer this protection (Antoun, 1982) Differences in the types and patterns of crime by women result from gender socialization. It is difficult to commit a major crime. Such as burglary or armed robbery. The types of crime in which women are involved include prostitution; vagrancy, and domestic violence committed by women are closely tied to their roles as mother, wives and lovers. Traditional roles still dominate the lives of both offenders male and female (Macions, 1993) The study of female crime is interesting but it has some problems. Crime may go unobserved, unnoted or unrecorded and because of this the official statistics may not indicate the real crime. In the present study the crimes committed by women are discussed within the context of Pakistani society and socio-cultural factors responsible for crimes committed by females.

\section{Methodology}

The micro-level study was based on primary data collected from field survey. By using the purposive sample technique a random sample of 100 female criminal respondents involved in different crimes i.e. zina, drugs, murder, theft and others were considered. The study was conducted in Adiala Jail, Rawalpindi District. To explore study objectives, a well designed interviewing schedule was prepared. Data thus collected was analyzed statistically.

\section{Results and Discussion:}

The present study revealed; that majority of the respondents were between 15-25 years of age, this indicated that most respondents had committed crime at a young age.




Figure 2: Age group of respondents



Figure 3: Education Level of respondents

$30 \%$ of the respondents were illiterate which shows that these females lack higher education, a very less number of females were educated.

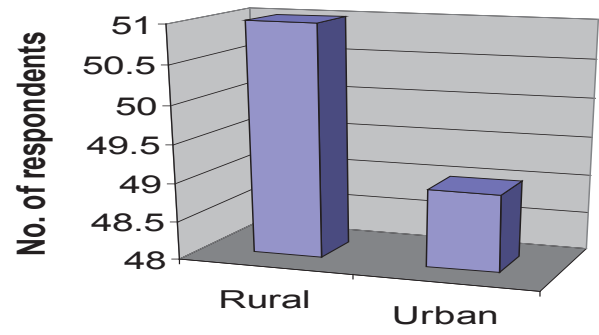

Area of residence

Figure 4: Residential Background of respondents

Majority of respondents belonged to rural background. This shows that women residing in rural areas committed more crimes than those residing in urban areas.

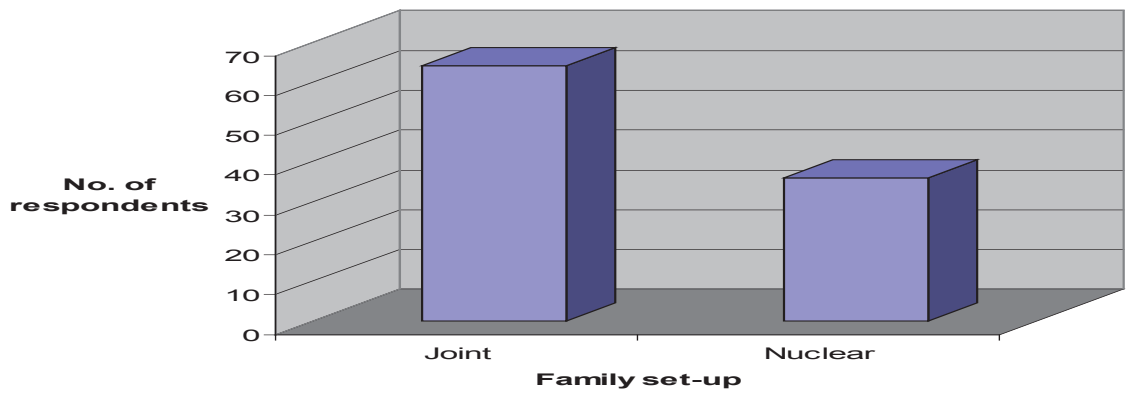


Figure 5: Family system of respondents

$64 \%$ of females belonged to joint family system which is less as compared to females committing crimes in nuclear family system.

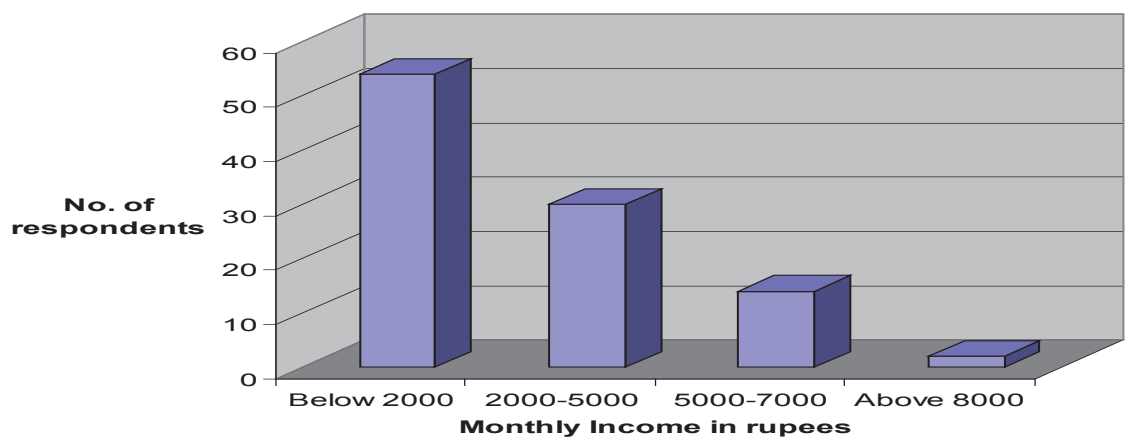

Figure 6: Monthly Income of respondents

The economic class of the respondents was determined on the basis of family income and occupation of respondent's family. 50\% of the offenders had income less than RsI000/month. 69\% of offenders are serving imprisonment due to major crime. Most of the respondents have said that it is their first conviction whereas 55\% said that they do not feel any guilt about committing the crime.

According to study $87 \%$ do not feel any psychological change in them due to imprisonment, which shows that criminals have a hard and cruel nature which cannot be affected by any hurdle. Economic conditions such as poverty and unemployment forced $39 \%$ of the offenders to commit the crime. $45 \%$ of these females complained about the bad attitude of Jail staff with them. While talking about the future planning of these female offenders $76 \%$ said that they would start a new life away from the hardships and cruelty of society. On the other hand there were many women who did not have any courage to face the society; they would rather spend their life within the safety of the jail. Most of these unfortunate women were victims of circumstances which were not created by them, but forced upon them by whims of their elders.

\section{Conclusions and Recommendations}

In a male dominant society like Pakistan the code of conduct is defined by the dominant group. But this does not mean that these rules of behavior are not violated. There may be disparity between an acknowledged norm and actual practice. Women may rebel and manipulate against such a socio-cultural set-up. The major causes of these crimes in our society are poverty, unemployment and lack of education. These factors compelled the offenders to use illegal means for their survival. The study revealed that the deviant women defied the conventional norms of behavior. When these norms are floated the social control exercised in a patriarchal society becomes evident. Deviancy among women highlights how women are defined and controlled in the society as a whole. Total prevention of crimes is impossible as disorganization to some extent is present in every society. The only measure possible foe prevention is to provide offenders with better chances and opportunities for their adjustment in society 
as normal members. The creation of healthy brotherhood, true followers of religion in its real spirit and a healthy society, culture and personality can solve the problems in the long run.

\section{References:}

Antoun, A.B. 1982. A study in the accommodation of traditions by American Anthropologist on modesty of women in Arab Muslim villages. American journal of Sociology. Vol. (5): 67I-697

Chambliss, W. J. 1975. Toward a political economy of crime: theory and society. Bull Publishing Company, California, U.S.A pp. I49-I70

Chaudry, M. I. 1984. Social theory: research and problem, Aziz Book Depot, Lahore, Pakistan. Pp.369-37I

Macions, D. 1993. The family: from institution to companionship $3^{\text {rd }}$ edition American Book Company, New York, USA

Marsh, L.1986. Sociology in focus. Longynan and New York. Vol.3. p.289

Pastner, A. B. 1974. Accommodation to purdha: the female perspective. Journal of Marriage and the Family. Monarch, New York, USA. 6:75

Smith, D. 1995. Criminology for social work. Macmillan Press Limited, Malaysia. P 3 I 
